\title{
Analysis of playing position and match status- related differences in external load demands on amateur handball: a case study
}

\section{Análise das diferenças de posição de jogo e status de jogo nas demandas de carga externa do handebol amador: um estudo de caso}

Pedro J. González-Haro ${ }^{1}$

(D) http://orcid.org/0000-0002-5621-0301

Carlos D. Gómez-Carmona ${ }^{2}$

(D) http://orcid.org/0000-0002-4084-8124

Alejandro Bastida-Castillo ${ }^{1,3}$

(D) http://orcid.org/0000-0002-8293-4549

Daniel Rojas-Valverde 4,5

(1) http://orcid.org/0000-0002-0717-8827

Manuel Gómez-López 1,6

(D) http://orcid.org/0000-0002-4595-3994

José Pino-Ortega ${ }^{1,6}$

(D) http://orcid.org/0000-0002-9091-0897

Abstract - Currently, the load quantification during training and competition in all sports is important to injury prevention, design specific training sessions, and player performance enhancement. The present study aimed to describe the external load profile of amateur-level handball players and to compare the playing position and match outcome-related differences in an official $2^{\text {nd }}$ Regional Division male official match. 19 handball players were monitored by WIMU PRO ${ }^{\mathrm{TM}}$ electronic performance and tracking systems (EPTS) with ultrawide-band (UWB) indoor location technology. Statistical analysis was composed of a t-student independent sample test and one-way ANOVA with Bonferroni posthoc. In amateur handball, most demands are composed of aerobic intensity displacements $(<12 \mathrm{~km} / \mathrm{h}, 76 \%$ playing time $)$ and low-intensity impacts $(<5 \mathrm{G})$. Differences were found between playing positions where wingers obtained the greatest values in high-intensity actions, centers in the volume of demands, and defensive specialist players in impacts. Besides, the winning teams performed greater highintensity demands both in displacements and speed changes. In conclusion, the present results realized the first approximation to handball amateur demands, considering the playing role and match status-related demands to design specific training plans.

Key words: Microtechnology; Monitoring; Sports; Workload.

Resumo - Atualmente, a quantificação da carga durante o treino e competição em todos os desportos é importante para a prevenção de lesões, sessões de treino especificas e melhoria do desempenho dos jogadores. Os objetivos do presente estudo foram descrever o perfil de carga externa dos jogadores de handebol a nivel amador e comparar a posição de jogo e as diferenças relacionadas com os resultados de um jogo oficial da $2^{a}$ Divisão Regional masculino. Foram analisados 19 jogadores de handebol por meio do WIMU PRO ${ }^{T M}$ electronic performance and tracking systems (EPTS) com tecnologia de localização em interiores ultrawide-band (UWB). A análise estatística foi composta por um teste $T$ para amostra independente e ANOVA unidirecional com posthoc de Bonferroni. No handebol amador, as maiores exigências são compostas por deslocamentos de intensidade aeróbica $(<12 \mathrm{~km} / \mathrm{h}, 76 \%$ de tempo de jogo) e impactos de baixa intensidade ( $<5 \mathrm{G})$. Foram encontradas diferenças entre as posições de jogo em que os alas obtiveram os maiores valores em açôes de alta intensidade, centros no volume de exigência e jogadores defensivos especializados em impactos. Além disso, as equipes vencedoras realizaram maiores exigências de alta intensidade, tanto em deslocamentos como em mudanças de velocidade. Esses resultados fazem a primeira aproximação às exigências do handebol amador, considerando as exigências relacionadas com o papel de jogo e status de jogo para desenhar planos de treino especificos.

Palavras-chave: Carga de trabalho; Esportes; Microtecnologia; Monitoramento.

1 University of Murcia. Campus of International Excellence "Mare Nostrum". Murcia, Spain.

2 University of Extremadura. Faculty of Sports Sciences. Training Optimization and Sports Performance Research Group. Caceres, Spain.

3 Isabel I University. Burgos, Spain.

4 Universidad Nacional. School of Human Movement Science and Quality of Life. Centre for Research and Diagnosis in Sport and Health. Heredia, Costa Rica.

5 University of Extremadura. Sport Science Faculty. Group of Sports Training and Physical Conditioning. Caceres, Spain.

6 University of Murcia. Faculty of Sport Sciences. Department of Physical Activity and Sport. Santiago de la Ribera, Murcia, Spain

Received: February 11, 2020 Accepted: May 15, 2020

How to cite this article González-Haro PJ, Gómez-Carmona CD, Bastida-Castillo A, Rojas-Valverde D, Gómez-López M, Pino-Ortega J. Analysis of playing position and match status-related differences in external load demands on amateur handball: a case study. Rev Bras Cineantropom Desempenho Hum 2020, 22:e71427. DOI: http://dx.doi.org/10.1590/19800037.2020v22e71427

Copyright: This work is licensed under a Creative Commons Attribution 4.0 International License. 


\section{INTRODUCTION}

Handball is a team sport that requires intermittent high-intensity actions, as accelerations, decelerations, changes of direction and speed, high-speed displacements, jumps, and landings ${ }^{1}$. Therefore, similarly to other team sports as basketball, football, or rugby, it is very important for team staff the design of training and the workload monitoring to analyze the demands during competition and prepare specifically for the worst-case scenario in handball matches ${ }^{2}$. In this sense, the study of physical demands of handballers has been one of the most investigated topics in the last decade, shown in standardized variables as total distance covered, speed profiles, high-intensity actions, or impacts during competition ${ }^{3,4}$.

Thanks to technological advances, electronic performance, and tracking systems (EPTS) have been developed that allow monitoring the skills and displacements of the players during training and competition ${ }^{5}$. Based on the specific demands of competition, different investigations have carried out an analysis to determine the physical, anthropometric, and physiological characteristics of handball players through $\mathrm{EPTS}^{6,7}$. These studies recommended that coaches should consider anthropometric and physical characteristics of handballers such as height, weight, fat percentage, muscle mass percentage, hand size, and arm perimeter when assessing the potential performance of young male and female players. In the same researches, other important key factors have been mentioned as throw speed, vertical jump height, aerobic capacity, maximum speed, and repeated sprint ability ${ }^{8}$.

Also, most studies realized in team sports have identified an effect of contextual variables as playing position ${ }^{9,10}$ and match outcome $e^{11,12}$ in soccer and basketball. In handball, it has been also identified that the physical demands performed are influenced by playing positions at elite-level ${ }^{1,13,14}$ and recreational-level ${ }^{7}$. Instead, in our knowledge, a lack of research about the effect of match outcome on the workload demands of the handball players both at elite-level and amateur-level has been identified. Therefore, the main purpose of the present study is to describe the workload demands in amateur-level handball players during an official competition game and identify differences between playing positions (center, backcourt, wing, pivot, and defensive specialist) and the match outcome (win or lose).

\section{METHODS \\ Participants}

Twenty-four handball players that competed in the $2^{\text {nd }}$ regional male division participated voluntarily in the present study. The inclusion criteria were: (a) not suffer any injury that prevents the sports practice before and during the game, (b) participate more than $50 \%$ of the playing time in each period, and (c) the goalkeepers were excluded from the study due to workload demands and technical-tactical actions differ to court players ${ }^{8}$. Therefore, a total of 19 handball players were analyzed in the present study.

A previous consent was requested from the Handball Regional Fed- 
eration, the referees, and both handball teams because the use of EPTS attached to the athlete during the regular handball season is prohibited, and all of them approved their utilization. Besides, all players signed informed consent before the data register. The study that was carried out following the bioethical considerations of the Declaration of Helsinki (2013), and was approved by the bioethics committee of the University of Murcia (Registration Code 2061/2018).

\section{Instruments}

An EPTS device called WIMU PRO ${ }^{\mathrm{TM}}$ (RealTrack Systems, Almeria, Spain) was used to monitor the external workload concerning the displacements performed by the players. This device has different sensors: (a) 4 triaxial accelerometers with a full scale of $\pm 16, \pm 16, \pm 32$ and $\pm 400 \mathrm{G}$, (b) 3 triaxial gyroscopes with a full scale of 2000 and 4000 degrees/second, (c) a 3D magnetometer, (d) a global navigation satellite system (GNSS) chip and (e) an ultrawide-band (UWB) chip. In the present study, the variables were obtained through raw accelerometer data with a sampling frequency of $100 \mathrm{~Hz}$ and UWB indoor tracking technology with a sampling frequency of $18 \mathrm{~Hz}$. Besides, the device dimensions are $81 \times 45 \times 16$ millimeters and weigh $70 \mathrm{gr}$ (see figure 1a). To attach the device on the player's body (upper back), an anatomically adjusted harness was used that locates the device at the level of the interscapular line (vertebrae T2-T4) (see figure 1a).

The device has previously been used both in outdoor sports ${ }^{15}$ and indoor sports ${ }^{10}$. Also, its reliability and validity have been previously evaluated for indoor conditions positioning in handball ${ }^{16}$, and the accelerometer reliability for external workload measurement in the sport context $t^{17}$.

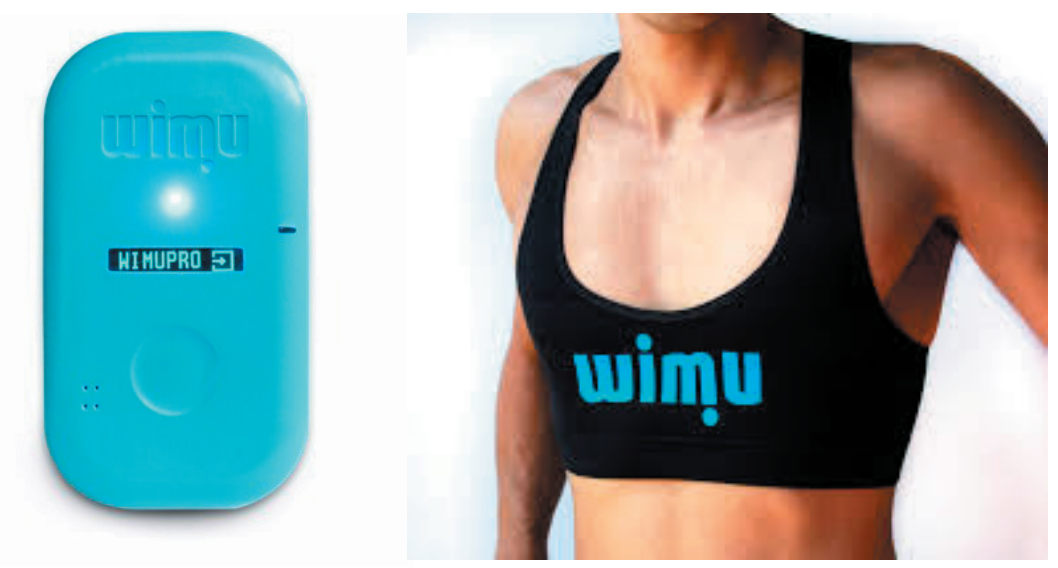

Figure 1. (a) Image of the WIMU PRO ${ }^{\mathrm{TM}}$ inertial device and (b) anatomical adjusted harness in one of the study participants.

\section{Variables}

External workload: The external workload variables analyzed in the present study are divided into three groups: (a) distance and speed of displacements, (b) neuromuscular load, and (c) speed changes. Due to the particularity of the substitutions and playing position changes during the game, only 
the relative variables per minute (e.g. relative distance, accelerations per minute) and the maximum values of each variable (maximum acceleration or maximum speed) were used due to they are more representative of the total volume and intensity in team sports with intermittent efforts (e.g. basketball, handball, soccer...) and should be used to provide more accurate information on the demands, regardless of playing time ${ }^{10}$. All analyzed variables are shown in table 1.

Match outcome: The analyzed teams were classified according to the final result of the match in (a) winner $(n=10)$ and (b) loser team $(n=9)$, with a final match outcome of 29-21 goals.

Playing positions: The handball players were divided in five playing positions: (a) center $(n=3)$, (b) backcourt $(n=6)$; (c) wing $(n=4)$; pivot $(n=4)$; defensive specialist $(n=2)$. Defensive specialist players made attack-defense substitutions based on the possession of the ball, and they always were located on the center position of the defensive system (5:1 and 6:0).

\section{Procedures}

Data were collected in March of 2018. The match was played between the CB San Lorenzo and Jimbee CAB Cartagena clubs of the league championship of the $2^{\text {nd }}$ National Senior Men's Division of the Region of Murcia, which started at 7:30 p.m. with an average temperature of $15^{\circ}$.

For the data monitoring, UWB system was installed on the court as follow: (a) six antennas were fixed around the track, two of them were located in the extension of the line midfield, one to each band, at a distance of $2 \mathrm{~m}$. of the line that delimits the field by its sides and the remaining four were placed in the respective 4 corners of the field, at a distance of $2.5 \mathrm{~m}$. in the prolongation of the diagonal line of each vertex (see figure 2); (b) the antennas were fixed through a tripod at $3 \mathrm{~m}$. tall; (c) once installed, they were turned on one by one ensuring that the master antenna was the last; (d) after switching on, a process of autocalibration of the antennas occurred during 5 'in which they calculate the position in $\mathrm{x}$ and $\mathrm{y}$ coordinates of all of them; and (e) finally the devices were turned on leaving them static, on a flat surface and without magnetic elements around for 1', so that they communicated with the antennas and are configured within the Cartesian plane created by them ${ }^{18}$.

Devices were placed on the athletes using an anatomically adjusted harness, as usually used in team sports. The first and second half temporary marks and the selection of the playing time of each handballer were made in real-time using a laptop with S Vivo Software. At the end of the match, the devices were removed from the players and placed at the charging station to download the raw information recorded during the match. Raw data were exported in Excel format and imported into the statistical software for statistical analysis.

\section{Data analysis}

The mean and standard deviation $(\mathrm{M} \pm \mathrm{SD})$ of the analyzed variables were used for the descriptive analysis. The distribution of the variables and the 
homogeneity of the variances were analyzed using Kolmogorov-Smirnov and Levene test, reporting a parametric distribution in all of them. For the inferential analysis based on the match result and the specific positions, the T-statistics for independent samples and one-way ANOVA were used, comparing them in pairs using Bonferroni. The effect size of the differences was calculated using Cohen's $\mathrm{d}(d)$ and squared partial omega $\left(\omega_{\mathrm{p}}{ }^{2}\right)$, respectively. The statistic d was interpreted as: $d>0.2$ small, $d>0.6$ moderate, $d>1.2$ large and $d>2.0$ very large and the statistic $\omega_{\mathrm{p}}{ }^{2}$ as $>0.01$ small; $>0.06$ moderate and $>0.14$ large ${ }^{19}$. Statistical analysis was performed using the Statistical Package for the Social Sciences software (version 24, IBM Corporation, Armonk NY, USA).

Table 1. Variables External workload variables analyzed in the present study.

\begin{tabular}{|c|c|c|c|c|}
\hline Group & Variable & Sub variable & $\begin{array}{l}\text { Acronym / Meas- } \\
\text { urement unit }\end{array}$ & Description \\
\hline \multirow{7}{*}{$\begin{array}{l}\text { Distance and } \\
\text { speed of dis- } \\
\text { placements }\end{array}$} & Distance relative & Total & $\mathrm{DR}(\mathrm{m} / \mathrm{min})$ & Total distance covered per minute \\
\hline & & Walking & $\mathrm{DR}_{\mathrm{z} 1}(\mathrm{~m} / \mathrm{min})$ & Total distance covered per minute between $0-6 \mathrm{~km} / \mathrm{h}$. \\
\hline & & Jogging & $\mathrm{DR}_{\mathrm{z2}}(\mathrm{m} / \mathrm{min})$ & Total distance covered per minute between $6-12 \mathrm{~km} / \mathrm{h}$. \\
\hline & & Running & $\mathrm{DR}_{\mathrm{z} 3}(\mathrm{~m} / \mathrm{min})$ & Total distance covered per minute between $12-18 \mathrm{~km} / \mathrm{h}$ \\
\hline & & High-intensity & $\mathrm{DR}_{\mathrm{z} 4}(\mathrm{~m} / \mathrm{min})$ & $\begin{array}{l}\text { Total distance covered per minute between 18-24 } \\
\mathrm{km} / \mathrm{h} \text {. }\end{array}$ \\
\hline & & Sprint & $\mathrm{DR}_{\mathrm{z5}}(\mathrm{m} / \mathrm{min})$ & $\begin{array}{l}\text { Total distance covered per minute between over than } \\
24 \mathrm{~km} / \mathrm{h} \text {. }\end{array}$ \\
\hline & Maximum speed & & $\mathrm{V}_{\text {MAX }}(\mathrm{km} / \mathrm{h})$ & Maximum speed reached. \\
\hline \multirow{8}{*}{$\begin{array}{l}\text { Neuromuscular } \\
\text { load }\end{array}$} & Impacts & Total & $\operatorname{Imp}(\mathrm{n} / \mathrm{min})$ & Total number of impacts per minute \\
\hline & & Low & $\operatorname{Imp} p_{z 1}(n / m i n)$ & Total number of impacts per minute $>3 \mathrm{G}$. \\
\hline & & Moderate & $\operatorname{Imp} p_{z 2}(n / m i n)$ & Total number of impacts per minute between 3-5G. \\
\hline & & High & $\operatorname{Imp}_{\mathrm{z3}}(\mathrm{n} / \mathrm{min})$ & Total number of impacts per minute between $5-8 \mathrm{G}$. \\
\hline & & Very high & $\operatorname{Imp}_{\mathrm{z4}}(\mathrm{n} / \mathrm{min})$ & Total number of impacts per minute $>8 \mathrm{G}$. \\
\hline & Jumps & & Jumps (n/min) & Total number of jumps per minute. \\
\hline & Steps & & Steps (n/min) & Total number of steps per minute. \\
\hline & Player Load & & $P L$ (a.u./ min) & $\begin{array}{l}\text { Accelerometry-based workload in the three axes of } \\
\text { movement per minute. }\end{array}$ \\
\hline \multirow{12}{*}{ Speed changes } & Accelerations & Total & $\operatorname{Acc}(\mathrm{n} / \mathrm{min})$ & Total accelerations per minute. \\
\hline & & Maximum & $\operatorname{Acc}_{\text {MAX }}\left(\mathrm{m} / \mathrm{s}^{2}\right)$ & Maximum acceleration reached. \\
\hline & & Low & $\mathrm{AcC}_{\mathrm{z} 1}(\mathrm{n} / \mathrm{min})$ & $\begin{array}{l}\text { Total accelerations per minute performed between } 0-1 \\
\mathrm{~m} / \mathrm{s}^{2}\end{array}$ \\
\hline & & Moderate & $\mathrm{Acc}_{\mathrm{z2}}(\mathrm{n} / \mathrm{min})$ & $\begin{array}{l}\text { Total accelerations per minute performed between 1-2 } \\
\mathrm{m} / \mathrm{s}^{2}\end{array}$ \\
\hline & & High & $\mathrm{Acc}_{\mathrm{z3}}(\mathrm{n} / \mathrm{min})$ & $\begin{array}{l}\text { Total accelerations per minute performed between } 2-3 \\
\mathrm{~m} / \mathrm{s}^{2}\end{array}$ \\
\hline & & Very high & $\mathrm{Acc}_{\mathrm{Z} 4}(\mathrm{n} / \mathrm{min})$ & Total accelerations per minute performed $>3 \mathrm{~m} / \mathrm{s}^{2}$ \\
\hline & Decelerations & Total & Dec & Total decelerations per minute. \\
\hline & & Maximum & $\operatorname{Dec}_{\text {MAX }}\left(\mathrm{m} / \mathrm{s}^{2}\right)$ & Maximum deceleration reached. \\
\hline & & Low & $\operatorname{Dec}_{z 1}(n / m i n)$ & $\begin{array}{l}\text { Total decelerations per minute performed between } 0-1 \\
\mathrm{~m} / \mathrm{s}^{2}\end{array}$ \\
\hline & & Moderate & $\mathrm{Dec}_{\mathrm{z2}}(\mathrm{n} / \mathrm{min})$ & $\begin{array}{l}\text { Total decelerations per minute performed between 1-2 } \\
\mathrm{m} / \mathrm{s}^{2}\end{array}$ \\
\hline & & High & $\mathrm{Dec}_{\mathrm{z3}}(\mathrm{n} / \mathrm{min})$ & $\begin{array}{l}\text { Total decelerations per minute performed between } 2-3 \\
\mathrm{~m} / \mathrm{s}^{2}\end{array}$ \\
\hline & & Very high & $\operatorname{Dec}_{z 4}(\mathrm{n} / \mathrm{min})$ & Total decelerations per minute performed $>3 \mathrm{~m} / \mathrm{s}^{2}$ \\
\hline
\end{tabular}




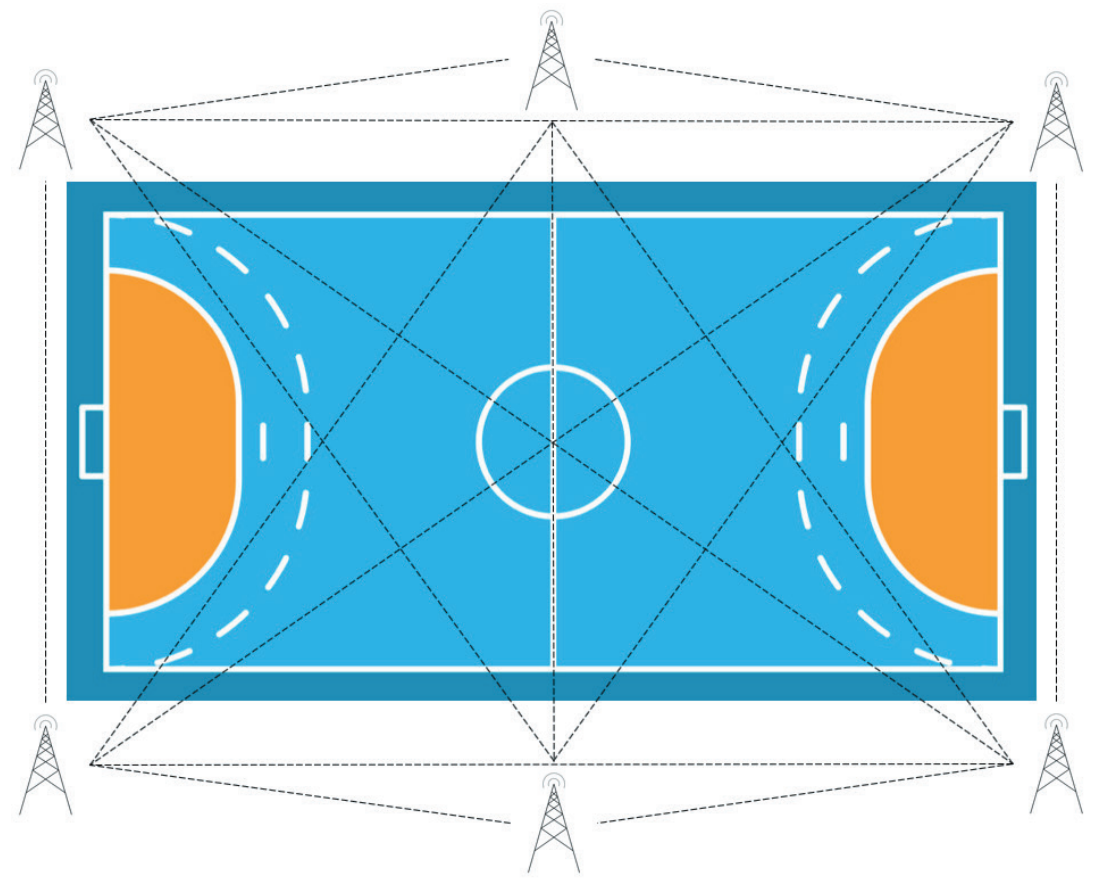

Figure 2. Distribution of antennas for the indoor location using UWB technology.

\section{RESULTS}

Table 2 shows the descriptive and inferential analysis of the external load variables analyzed in the present investigation according to the specific position.

Significant differences were found between specific positions with a moderate effect size in $\mathrm{DR}_{\mathrm{Z} 4}\left(F=6.26 ; p<.01 ; \omega_{p}^{2}=0.07\right.$; end $>$ pivot=backcourt=ce ntre=defense $)$ and $\operatorname{Acc}_{\operatorname{MAX}}\left(F=5.38 ; \mathrm{p}<.01 ; \omega \mathrm{p}^{2}=0.06\right.$; end $>$ pivot=backcourt $)$ and with a small effect size in $\mathrm{DR}_{\mathrm{Z} 3}\left(\mathrm{~F}=2.73 ; \mathrm{p}=.04 ; \omega \mathrm{p}^{2}=0.02\right.$; backcourt> end), $\mathrm{DR}_{\mathrm{Z} 5}\left(\mathrm{~F}=4.51 ; \mathrm{p}<.01 ; \omega \mathrm{p}^{2}=0.05\right.$; end $>$ pivot=backcourt=defense), $\mathrm{V}_{\text {MAX }}\left(\mathrm{F}=4.07 ; \mathrm{p}<.01 ; \omega \mathrm{p}^{2}=0.05 ;\right.$ end $>$ pivot=defense $), \operatorname{Imp}_{\mathrm{Z} 4}(\mathrm{~F}=2.69 ; \mathrm{p}=.04$; $\omega \mathrm{p}^{2}=0.02$; centre $>$ defense), jumps $\left(\mathrm{F}=4.64 ; \mathrm{p}<.01 ; \omega \mathrm{p}^{2}=0.05\right.$; defense $>$ wing $)$, $\operatorname{Acc}_{\mathrm{Z} 1}\left(\mathrm{~F}=2.67 ; \mathrm{p}=.04 ; \omega \mathrm{p}^{2}=0.02 ;\right.$ backcourt $>$ pivot $), \operatorname{Acc}_{\mathrm{Z} 2}(\mathrm{~F}=2.52$; $\mathrm{p}=.05 ; \omega \mathrm{p}^{2}=0.01 ;$ pivot $>$ defense $), \operatorname{Acc}_{\mathrm{Z} 4}\left(\mathrm{~F}=3.41 ; \mathrm{p}=.01 ; \omega_{\mathrm{p}}^{2}=0.04\right.$; end $>$ backcourt=centre) and $\operatorname{Dec}_{\mathrm{Z} 2}\left(\mathrm{~F}=3.10 ; \mathrm{p}=.02 ; \omega \mathrm{p}^{2}=0.03\right.$; backcourt $>$ wing $)$.

Table 3 shows the descriptive and inferential analysis of the external load variables analyzed in this investigation based on the final result of the match.

The winning teams obtained higher values with a very large effect size in the DRZ4 and DecZ4 variables and large effect size in DR, DRZ3, ImpZ2, steps, PL, AccZ3, AccZ4, DecMAX and DecZ3. The losers obtained higher values with a large effect size in the ImpZ1 variable.

\section{DISCUSSION}

The monitoring of the load in competition and the individualization according to the specific characteristics of the players is fundamental for 
Table 2. Descriptive and inferential analysis of external load variables recorded according to the specific position.

\begin{tabular}{|c|c|c|c|c|c|c|c|}
\hline Variable & $\begin{array}{c}\text { Pivot } \\
M \pm S . D \text {. }\end{array}$ & $\begin{array}{l}\text { Backcourt } \\
\text { M } \pm \text { S.D. }\end{array}$ & $\begin{array}{l}\text { Centre } \\
M \pm S . D \text {. }\end{array}$ & $\begin{array}{c}\text { Wing } \\
M \pm S . D \text {. }\end{array}$ & $\begin{array}{l}\text { Defense } \\
M \pm S . D \text {. }\end{array}$ & $F(p)$ & $\begin{array}{c}\text { Partial omega } \\
\text { squared } \\
\text { (effect) }\end{array}$ \\
\hline $\mathrm{DR}$ (m/min) & $71.48 \pm 12.09$ & $68.78 \pm 19.73$ & $74.88 \pm 22.62$ & $78.59 \pm 13.26$ & $58.14 \pm 11.58$ & $1.60(.19)$ & 0.00 \\
\hline $\mathrm{DR}_{\mathrm{z} 1}(\mathrm{~m} / \mathrm{min})$ & $31.42 \pm 3.73$ & $32.12 \pm 9.77$ & $33.67 \pm 7.48$ & $31.48 \pm 3.30$ & $27.33 \pm 7.82$ & $0.71(.59)$ & 0.00 \\
\hline $\mathrm{DR}_{\mathrm{z} 2}(\mathrm{~m} / \mathrm{min})$ & $22.86 \pm 4.53$ & $21.64 \pm 7.24$ & $27.07 \pm 9.31$ & $23.18 \pm 6.45$ & $16.97 \pm 2.74$ & $2.10(.09)$ & 0.00 \\
\hline $\mathrm{DR}_{\mathrm{z} 3}(\mathrm{~m} / \mathrm{min})$ & $15.17 \pm 4.36$ & $12.33 \pm 6.18$ & $11.81 \pm 5.49$ & $18.35 \pm 5.72^{b}$ & $12.48 \pm 4.02$ & $2.73(.04)$ & 0.02 small \\
\hline $\mathrm{DR}_{\mathrm{Z4}}(\mathrm{m} / \mathrm{min})$ & $1.89 \pm 1.41$ & $2.33 \pm 1.58$ & $2.16 \pm 2.37$ & $4.75 \pm 1.65^{\text {abce }}$ & $1.33 \pm 1.10$ & $6.26(<.01)$ & 0.07 moderate \\
\hline $\mathrm{DR}_{\mathrm{z5}}(\mathrm{m} / \mathrm{min})$ & $0.14 \pm 0.29$ & $0.36 \pm 0.57$ & $0.16 \pm 0.20$ & $0.83 \pm 0.63^{\text {ace }}$ & $0.03 \pm 0.05$ & $4.51(<.01)$ & 0.05 small \\
\hline $\mathrm{V}_{\text {MAX }}(\mathrm{km} / \mathrm{h})$ & $18.79 \pm 1.36$ & $20.01 \pm 2.47$ & $19.32 \pm 1.46$ & $21.29 \pm 0.62^{\mathrm{ae}}$ & $18.59 \pm 0.34$ & $4.07(<.01)$ & 0.05 small \\
\hline Imp (n/min) & $51.24 \pm 12.72$ & $49.38 \pm 18.89$ & $52.35 \pm 8.35$ & $56.54 \pm 4.97$ & $59.41 \pm 7.19$ & $0.92(.46)$ & 0.00 \\
\hline $\operatorname{Imp} p_{\mathrm{z} 1}(\mathrm{n} / \mathrm{min})$ & $36.59 \pm 13.56$ & $36.92 \pm 17.09$ & $35.99 \pm 5.49$ & $44.30 \pm 6.24$ & $50.48 \pm 7.87$ & $2.04(.10)$ & 0.00 \\
\hline $\operatorname{Imp}_{\mathrm{z} 2}(\mathrm{n} / \mathrm{min})$ & $11.39 \pm 5.90$ & $9.59 \pm 3.23$ & $12.43 \pm 5.57$ & $9.80 \pm 4.19$ & $7.40 \pm 1.34$ & $1.47(.23)$ & 0.00 \\
\hline $\operatorname{Imp}_{\mathrm{z3}}(\mathrm{n} / \mathrm{min})$ & $3.01 \pm 3.28$ & $2.53 \pm 0.94$ & $3.29 \pm 2.02$ & $2.08 \pm 1.07$ & $1.46 \pm 0.32$ & $1.22(.32)$ & 0.00 \\
\hline $\operatorname{Imp}_{\mathrm{z} 4}(\mathrm{n} / \mathrm{min})$ & $0.25 \pm 0.47$ & $0.35 \pm 0.17$ & $0.64 \pm 0.62^{\mathrm{e}}$ & $0.35 \pm 0.16$ & $0.08 \pm 0.06$ & $2.69(.04)$ & 0.02 small \\
\hline Jumps (n/min) & $0.10 \pm 0.05$ & $0.16 \pm 0.08^{d}$ & $0.15 \pm 0.05$ & $0.07 \pm 0.04$ & $0.17 \pm 0.06^{d}$ & $4.64(<.01)$ & 0.05 small \\
\hline Steps (n/min) & $58.57 \pm 14.85$ & $51.85 \pm 16.96$ & $63.17 \pm 19.65$ & $56.41 \pm 14.05$ & $44.45 \pm 8.52$ & $1.56(.20)$ & 0.00 \\
\hline PL (a.u./ min) & $0.83 \pm 0.21$ & $0.70 \pm 0.19$ & $0.82 \pm 0.27$ & $0.72 \pm 0.16$ & $0.59 \pm 0.10$ & $1.99(.11)$ & 0.00 \\
\hline Acc (n/min) & $17.94 \pm 0.76$ & $18.40 \pm 3.29$ & $18.24 \pm 1.74$ & $17.84 \pm 1.92$ & $16.77 \pm 2.67$ & $0.55(.70)$ & 0.00 \\
\hline $\operatorname{Acc}_{\text {MAX }}\left(\mathrm{m} / \mathrm{s}^{2}\right)$ & $3.19 \pm 0.50$ & $3.18 \pm 0.44$ & $3.42 \pm 0.36$ & $3.89 \pm 0.53^{\mathrm{ab}}$ & $3.56 \pm 0.17$ & $5.38(<.01)$ & 0.06 moderate \\
\hline $\mathrm{Acc}_{\mathrm{z} 1}(\mathrm{n} / \mathrm{min})$ & $10.30 \pm 1.66$ & $12.01 \pm 2.09^{a}$ & $11.66 \pm 1.25$ & $10.97 \pm 0.72$ & $10.14 \pm 1.95$ & $2.67(.04)$ & 0.02 small \\
\hline $\mathrm{Acc}_{\mathrm{z} 2}(\mathrm{n} / \mathrm{min})$ & $5.53 \pm 1.37^{\mathrm{e}}$ & $4.73 \pm 1.24$ & $4.35 \pm 1.12$ & $4.26 \pm 0.75$ & $4.11 \pm 0.70$ & $2.52(.05)$ & 0.01 small \\
\hline $\mathrm{Acc}_{\mathrm{z} 3}(\mathrm{n} / \mathrm{min})$ & $1.84 \pm 0.33$ & $1.47 \pm 0.58$ & $1.83 \pm 0.67$ & $1.79 \pm 0.71$ & $1.98 \pm 0.29$ & $1.46(.23)$ & 0.00 \\
\hline $\mathrm{Acc}_{\mathrm{z} 4}(\mathrm{n} / \mathrm{min})$ & $0.27 \pm 0.46$ & $0.14 \pm 0.18$ & $0.02 \pm 0.03$ & $0.65 \pm 0.76^{b c}$ & $0.21 \pm 0.24$ & $3.41(.01)$ & 0.04 small \\
\hline $\operatorname{Dec}(\mathrm{n} / \mathrm{min})$ & $17.69 \pm 0.88$ & $18.33 \pm 3.26$ & $18.15 \pm 1.72$ & $17.73 \pm 1.91$ & $16.37 \pm 2.55$ & $0.82(.52)$ & 0.00 \\
\hline $\operatorname{Dec}_{\text {MAX }}\left(\mathrm{m} / \mathrm{s}^{2}\right)$ & $-3.31 \pm 0.43$ & $-3.17 \pm 0.54$ & $-3.39 \pm 0.32$ & $-3.69 \pm 0.54$ & $-3.37 \pm 0.20$ & $2.20(.08)$ & 0.00 \\
\hline $\mathrm{Dec}_{\mathrm{z} 1}(\mathrm{n} / \mathrm{min})$ & $10.68 \pm 1.41$ & $12.35 \pm 2.17^{d}$ & $11.90 \pm 1.24$ & $11.23 \pm 0.97$ & $10.01 \pm 2.06$ & $3.10(.02)$ & 0.03 small \\
\hline $\mathrm{Dec}_{\mathrm{z} 2}(\mathrm{n} / \mathrm{min})$ & $5.39 \pm 1.08$ & $4.51 \pm 1.36$ & $4.48 \pm 0.97$ & $4.63 \pm 1.32$ & $4.57 \pm 0.80$ & $1.13(.35)$ & 0.00 \\
\hline $\mathrm{Dec}_{\mathrm{z} 3}(\mathrm{n} / \mathrm{min})$ & $1.30 \pm 0.45$ & $1.24 \pm 0.47$ & $1.55 \pm 0.47$ & $1.43 \pm 0.69$ & $1.62 \pm 0.31$ & $0.99(.43)$ & 0.00 \\
\hline $\mathrm{Dec}_{\mathrm{z} 4}(\mathrm{n} / \mathrm{min})$ & $0.32 \pm 0.29$ & $0.23 \pm 0.29$ & $0.23 \pm 0.21$ & $0.45 \pm 0.40$ & $0.18 \pm 0.08$ & $1.33(.27)$ & 0.00 \\
\hline
\end{tabular}

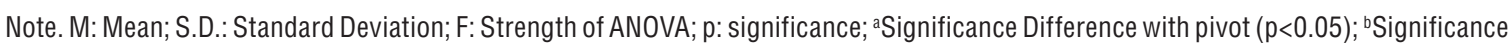
Difference with backcourt $(p<0.05)$; ' Significance Difference with centre $(p<0.05)$; ${ }^{d}$ Significance Difference with wing $(p<0.05)$; eSignificance Difference with defense $(p<0.05)$.

the design of training tasks and specific fitness programs in team sports ${ }^{2}$. Therefore, the present study aimed to describe the external workload of senior amateur handball players in official competition and analyze the differences in the specific positions and the match outcome. The amateur handball player covers $72.12 \mathrm{~m} / \mathrm{min}$, of which almost all is done walking and jogging (76\%), receiving a total of 54.23 impacts per minute, the majority being low intensity (84\%) caused by the displacement, in addition to 18 accelerations per minute, almost all of them of low intensity $(<3 \mathrm{~m} /$ $\left.\mathrm{s}^{2}\right)$ with $96 \%$ of all. Concerning the specific position, the wing is the one with the greatest requirements, especially in high-intensity actions, the backcourt one is the one with the greatest number of speed changes and finally, the centers and the defenses are the ones with the greatest demands at low intensity. Finally, the winner of the match presented higher values in the relative distance, high-intensity distance, and high-intensity speed changes with large effect sizes. 
Table 3. Descriptive and inferential analysis of the external load variables recorded according to the final result of the match.

\begin{tabular}{|c|c|c|c|c|}
\hline Variable & $\begin{array}{l}\text { Winner } \\
M \pm S . D .\end{array}$ & $\begin{array}{l}\text { Loser } \\
M \pm S . D .\end{array}$ & $t(p)$ & $d$ (effect) \\
\hline $\mathrm{DR}(\mathrm{m} / \mathrm{min})^{\star}$ & $83.43 \pm 7.72$ & $73.56 \pm 5.76$ & $2.43(.03)$ & 1.469 high \\
\hline $\mathrm{DR}_{\mathrm{z} 1}(\mathrm{~m} / \mathrm{min})$ & $32.97 \pm 2.29$ & $35.38 \pm 3.98$ & $-1.26(.24)$ & \\
\hline $\mathrm{DR}_{\mathrm{z} 2}(\mathrm{~m} / \mathrm{min})$ & $25.65 \pm 3.34$ & $23.32 \pm 5.13$ & $0.91(.39)$ & \\
\hline $\mathrm{DR}_{\mathrm{z3}}(\mathrm{m} / \mathrm{min})^{*}$ & $19.76 \pm 4.72$ & $12.74 \pm 4.84$ & $2.43(.03)$ & 1.467 high \\
\hline $\mathrm{DR}_{\mathrm{z} 4}(\mathrm{~m} / \mathrm{min})^{*}$ & $4.49 \pm 1.73$ & $1.68 \pm 0.82$ & $3.52(<.01)$ & 2.142 very high \\
\hline $\mathrm{DR}_{\mathrm{z5}}(\mathrm{m} / \mathrm{min})$ & $0.56 \pm 0.53$ & $0.45 \pm 0.62$ & $0.33(.75)$ & \\
\hline $\mathrm{V}_{\text {MAX }}(\mathrm{km} / \mathrm{h})$ & $20.56 \pm 1.28$ & $20.42 \pm 1.87$ & $0.15(.89)$ & \\
\hline Imp (n/min) & $52.69 \pm 8.78$ & $56.45 \pm 9.84$ & $-0.67(.52)$ & \\
\hline $\operatorname{Imp}_{\mathrm{z} 1}(\mathrm{n} / \mathrm{min})^{*}$ & $34.30 \pm 7.88$ & $44.74 \pm 8.02$ & $-2.17(.05)$ & -1.312 high \\
\hline $\operatorname{Imp} p_{z 2}(n / m i n)^{\star}$ & $14.11 \pm 4.10$ & $9.04 \pm 2.11$ & $2.64(.03)$ & 1.600 high \\
\hline $\operatorname{Imp} p_{\mathrm{z} 3}(\mathrm{n} / \mathrm{min})$ & $3.87 \pm 2.86$ & $2.31 \pm 0.84$ & $1.17(.27)$ & \\
\hline $\operatorname{Imp} p_{z 4}(\mathrm{n} / \mathrm{min})$ & $0.42 \pm 0.41$ & $0.35 \pm 0.22$ & $0.35(.74)$ & \\
\hline Jumps (n/min) & $0.11 \pm 0.05$ & $0.14 \pm 0.07$ & $-0.58(.59)$ & \\
\hline Steps $(\mathrm{n} / \mathrm{min})^{*}$ & $67.67 \pm 6.91$ & $53.83 \pm 9.18$ & $2.86(.02)$ & 1.681 high \\
\hline $\mathrm{PL}(\text { a.u. } / \mathrm{min})^{*}$ & $0.90 \pm 0.13$ & $0.74 \pm 0.05$ & $2.72(.02)$ & 1.686 high \\
\hline $\operatorname{Acc}(\mathrm{n} / \mathrm{min})$ & $18.94 \pm 1.01$ & $18.88 \pm 1.44$ & $0.07(.95)$ & \\
\hline $\operatorname{Acc}_{\text {MAX }}\left(m / s^{2}\right)$ & $3.75 \pm 0.60$ & $3.19 \pm 0.36$ & $1.90(.09)$ & \\
\hline $\mathrm{AcC}_{\mathrm{z} 1}(\mathrm{n} / \mathrm{min})$ & $10.77 \pm 1.41$ & $12.05 \pm 1.89$ & $-1.29(.23)$ & \\
\hline $\mathrm{Acc}_{\mathrm{z2}}(\mathrm{n} / \mathrm{min})$ & $5.36 \pm 0.80$ & $5.20 \pm 1.01$ & $0.28(.78)$ & \\
\hline $\mathrm{AcC}_{\mathrm{z} 3}(\mathrm{n} / \mathrm{min})^{\star}$ & $2.09 \pm 0.33$ & $1.48 \pm 0.46$ & $2.52(.03)$ & 1.501 high \\
\hline $\mathrm{Acc}_{\mathrm{Z} 4}(\mathrm{n} / \mathrm{min})^{*}$ & $0.72 \pm 0.64$ & $0.00 \pm 0.00$ & $2.76(.03)$ & 1.674 high \\
\hline $\operatorname{Dec}(n / m i n)$ & $18.74 \pm 1.21$ & $18.80 \pm 1.46$ & $-0.07(.95)$ & \\
\hline $\operatorname{Dec}_{\operatorname{MAX}}\left(\mathrm{m} / \mathrm{s}^{2}\right)^{\star}$ & $-3.75 \pm 0.50$ & $-3.14 \pm 0.23$ & $-2.69(.03)$ & -1.619 high \\
\hline $\mathrm{Dec}_{\mathrm{z} 1}(\mathrm{n} / \mathrm{min})$ & $11.04 \pm 1.30$ & $12.46 \pm 2.03$ & $-1.41(.19)$ & \\
\hline $\operatorname{Dec}_{\mathrm{z} 2}(\mathrm{n} / \mathrm{min})$ & $5.46 \pm 0.48$ & $5.06 \pm 1.15$ & $0.78(.45)$ & \\
\hline $\operatorname{Dec}_{z 3}(\mathrm{n} / \mathrm{min})^{*}$ & $1.67 \pm 0.46$ & $1.16 \pm 0.30$ & $2.21(.05)$ & 1.340 high \\
\hline $\operatorname{Dec}_{\mathrm{Z4}}(\mathrm{n} / \mathrm{min})^{\star}$ & $0.57 \pm 0.30$ & $0.11 \pm 0.09$ & $3.56(<.01)$ & 2.166 very high \\
\hline
\end{tabular}

Note. M: Mean; S.D.: Standard Deviation; t: Strength t; p: significance; d: Effect Size with Cohen's d. Bold values indicate the maximum value; 'Significance Difference between the winner and loser $(p<.05)$.

Concerning the distance and speed parameters, after analyzing the results of all the players together, we obtain an average distance traveled of $2551.42 \pm 1102.12$ meters lower value than in the studies of Belka et al. ${ }^{20}$ and Michalsik et al. ${ }^{13}$ with results of between 3399-to-4002 meters covered. Regarding the distance covered per minute, 72.12 meters were obtained, which resembles the results of other studies ${ }^{20,21}$. These differences between the total distance covered and the distance covered per minute are due to the time that each player was on the court since in amateur handball there is usually an equitable distribution of the minutes of play among all aligned players. In this way, a smaller total distance is covered, but the parameters of distance covered per minute are kept high. Regarding the intensity of the displacements, different studies the studies carried out in senior male and female elite-level handball showed that most of the distance traveled was done on walking or at low-medium intensity, below $12 \mathrm{~km} / \mathrm{h}$ 
( $76 \%$ of the distance covered) $)^{13,14,20}$. Therefore, in this sport modality, the development of aerobic metabolism is important for the improvement of sports performance.

Regarding the neuromuscular load, most of the impacts made did not exceed 5G (92\%), making a total of 54.23 impacts per minute over the entire range of intensities. There are no studies that show data on impacts greater than $8 \mathrm{G}$ forces performed by handball teams during the competition. However, if there is information about impacts made at more than $5 \mathrm{G}$ of force during the match ${ }^{22}$ with results very similar to those of the present study on impacts made at more than $5 \mathrm{G}$ (13.6 impacts $>5 \mathrm{G})$. Jumps are the specific action in which lower values are found in comparison with the literature in elite handball. Chelly et al. ${ }^{23}$ and Póvoas et al. ${ }^{14}$ in junior and senior handball found values of 6.9 and 4.9 jumps per player during the match respectively, higher than the 4.26 jumps recorded in this study. Finally, regarding the PL variable, there are demands per minute of $0.75 \pm 0.18$ a.u. $/ \mathrm{min}$. These demands are lower than those found in elite handball $(9.52 \pm 1.1$ vs. $7.5 \pm 1.8)$.

Finally, regarding the quantification of speed changes, it has not been studied in depth until now ${ }^{24}$. In this study finds an average of 0.70 accelerations per minute and 1.05 decelerations per minute above $2.5 \mathrm{~m} / \mathrm{s}^{2}$, similar to those of the present study. Instead, Manchado et al. ${ }^{25}$ find higher results in acceleration and deceleration 1 and 2 with respect to those obtained in the present work. The causes of this great difference are due to the level of the participants between investigations. Therefore, the individualization of the load is essential for the improvement of performance between categories and sports levels, due to its specific requirements.

In relation to the results obtained, the end is the specific position that carries out the greatest external load, since it obtains results greater than the rest in the parameters of distance traveled per minute, displacements at high-intensity, and accelerations and decelerations of high intensity. These results are similar to those found by Cardinale et al. ${ }^{21}$ and Michalsik and Aagard $^{6}$. These results could be explained because the extremes are the players that make up the first wave of the counterattack every time there is a change of possession, either after a goal kick of the opposing team that was not between the 3 sticks, for a goalkeeper stop, or a steal ${ }^{26}$. Also, in this match, team A maintained a 5:1 defensive system throughout the match, whose outpost was always occupied by the end of the side, depending on the moment of the match. This advanced defender deals with covering pass lines between the players of the first line of attack, and to be effective, he must make a large number of changes in direction and pace, being this outpost of high physical, technical and tactical qualification ${ }^{27}$.

In this study, the center, backcourt, and wing positions are those that receive the highest number of impacts greater than $8 \mathrm{G}$ forces per minute on average (15.67 center, 15.50 backcourt, 14.57 wing), while the pivot position and defensive specialist were those with the lowest results $(3.00$ and 3.50 respectively), which is the opposite of the results obtained by 
Póvoas et al. ${ }^{14}$ where the highest values of impacts $>5 \mathrm{G}$ are received by the pivot. The difference between studies may be because most of the impacts received by the pivot are $5-8 \mathrm{G}$ of force, but to know for sure it would be convenient to carry out future studies with that objective.

Finally, concerning speed changes, the wings also obtained the highest number of accelerations and decelerations per minute at high intensity, while in zone 1 the results are more balanced among all players. In the study by Manchado et al. ${ }^{25}$ the same results were obtained in the accelerations $>3 \mathrm{~m} / \mathrm{s}^{2}$ and in the decelerations $<-3 \mathrm{~m} / \mathrm{s}^{2}$ (zone 4), while in the acceleration and deceleration zone 1 of this study the wings remain the ones with the highest number of accelerations and decelerations per minute performed.

This study shows how the winning team has greater relative distance, high-intensity distance, and high-intensity accelerations and decelerations compared to the winning team. This fact has been analyzed in handball in relation to technical-tactical action ${ }^{28,29}$ but not related to external load demands. This aspect has been studied in other sports disciplines such as basketball ${ }^{10}$ or soccer ${ }^{30}$ finding greater efforts of high-intensity actions in winner teams than the losing teams. Therefore, teams that have the highest acceleration and high-intensity displacement capacity are more likely to win the games compared to teams with a higher volume of low-intensity demands in their game, especially in offensive actions.

Although the results of the present investigation make the first approximation in the description of the external load carried out by two senior handball teams of amateur level, finding differences between the requirements for specific positions and identifying physical performance indicators between the winning and losing teams, some limitations should be considered. The results obtained cannot be extrapolated to the rest of the sports categories and levels, even to the specific characteristics of the study population due to the small sample (an official competition game in regular phase). Although, this research is a pioneer because it is the first that describes the demands in indoor handball using a new radio frequency-based tracking technology (UWB). Future research should deepen the study of amateur handball, both at the senior level and the youth level, due to the lack of study at this sports level in addition to where there is the greatest number of licenses and research in this area would have a greater social impact.

\section{CONCLUSIONS}

Based on the results obtained from this study, we can identify the following conclusions and practical applications: 1 . Amateur senior handball players covered an average distance of $2.5 \mathrm{~km}$ during the match, making $76 \%$ of that distance at a speed of less than $12 \mathrm{~km} / \mathrm{h}$, which shows the great prominence of aerobic metabolism during the handball competition. On average, they travel 309.56 meters with an acceleration greater than $1.12 \mathrm{~m} /$ $\mathrm{s}^{2}$, receive 11.47 impacts greater than $8 \mathrm{G}$ of force, and perform 4.26 jumps 
per game. 2. The wing is the player who receives the highest external load in almost all parameters in relation to the rest of the specific positions, and it is because that the wing is the player who performed most of the team's short, explosive and anaerobic actions during the competition. The center makes the highest number of low-intensity demands and defensive players are the ones who receive the highest number of impacts due to their role during the game. 3. The intermittent actions of high intensity (relative distance, distance at high intensity, accelerations, and decelerations of high intensity) are those that are performed in the most important situations of the game and that differentiate success in the final result. Therefore, handball players must have a high-level of anaerobic power and the ability to perform high-intensity action repeatedly during the competition.

\section{COMPLIANCE WITH ETHICAL STANDARDS}

\section{Funding}

The author Carlos D. Gómez Carmona was supported by a grant from the Spanish Ministry of Science, Innovation, and Universities (FPU17/00407). This research did not receive any specific grant from funding agencies in the public, commercial, or no-profit sectors. This study was funded by the authors.

\section{Ethical approval}

Ethical approval was obtained by the Bioethics Committee of the University of Murcia (number 2061/2018) and the protocol was written in accordance with standards set by the Declaration of Helsinki.

\section{Conflict of interest statement}

The authors have no conflict of interest to declare.

\section{Author Contributions}

Developed and coordinated the study: MG-L and JP-O; Helped in data collection: PJG-H, MG-L, and JP-O; Data analysis: CDG-C and ABC; Wrote the article: PJG-H, MG-L, JP-O, CDG-C, AB-C, and DR-V; Critical review of the article: $\mathrm{MG}-\mathrm{L}$ and JP-O.

\section{REFERENCES}

1. Karcher C, Buchheit M. On-court demands of elite handball, with special reference to playing positions. Sports Med 2014;44(6):797-814.

2. Cunningham DJ, Shearer DA, Carter N, Drawer S, Pollard B, Bennett M, et al. Assessing worst case scenarios in movement demands derived from global positioning systems during international rugby union matches: Rolling averages versus fixed length epochs. Sunderland C, editor. Plos One 2018;13(4):195-197.

3. Bartlett JD, O'Connor F, Pitchford N, Torres-Ronda L, Robertson SJ. Relationships between internal and external training load in team-sport athletes: Evidence for an individualized approach. Int J Sports Physiol Perform 2017;12(2):230-234.

4. Rojas-Valverde D, Gómez-Carmona CD, Gutiérrez-Vargas R, Pino-Ortega J. From big data mining to technical sport reports: the case of inertial measurement units. BMJ Open Sport Exerc Med 2019;5(1):e000565. 
5. FIFA. The approval of electronic performance tracking systems (EPTS) devices. Zurich Switzerland: Federation Internationale de Football Association. Circular No.:1494; 2015.

6. Michalsik LB, Aagaard P. Physical demands in elite team handball: Comparisons between male and female players. J Sports Med Phys Fitness 2015;55(9):878-891.

7. Póvoas SCA, Castagna C, Resende C, Coelho EF, Silva P, Santos R, et al. Physical and physiological demands of recreational team handball for adult untrained men. BioMed Res Int 2017; 1-10.

8. Wagner H, Finkenzeller T, Würth S, von Duvillard SP. Individual and team performance in team-handball: A review. J Sports Sci Med 2014;13(4):808.

9. Di Salvo V, Baron R, Tschan H, Calderon Montero F, Bachl N, Pigozzi F. Performance characteristics according to playing position in elite soccer. Int J Sports Med 2007;28(3):222-227.

10. Pino-Ortega J, Rojas-Valverde D, Gómez-Carmona CD, Bastida-Castillo A, Hernández-Belmonte A, García-Rubio J, et al. Impact of contextual factors on external load during a congested-fixture tournament in elite U'18 basketball players. Front Psychol 2019;10:1100.

11. Gómez-Carmona CD, Bastida-Castillo A, García-Rubio J, Pino-Ortega J, Ibáñez SJ. Game outcome influence in external load demands in youth male basketball during official competition. Cuad Psicol Deporte 2019;19(1):262-274.

12. Reche-Soto P, Cardona-Nieto D, Diaz-Suarez A, Bastida-Castillo A, GomezCarmona C, Garcia-Rubio J, et al. Player load and metabolic power dynamics as load quantifiers in soccer. J Hum Kinet 2019;69:259-269.

13. Michalsik L, Aagaard P, Madsen K. Locomotion Characteristics and matchinduced impairments in physical performance in male elite team handball players. Int J Sports Med 2012;34(07):590-599.

14. Póvoas SC, Seabra AF, Ascensão AA, Magalhães J, Soares JM, Rebelo AN. Physical and physiological demands of elite team handball. J Strength Cond Res 2012;26(12):3365-3375.

15. Gómez-Carmona C, Gamonales J, Pino-Ortega J, Ibáñez S. Comparative analysis of load profile between small-sided games and official matches in youth soccer players. Sports 2018;6(4):173.

16. Bastida-Castillo A, Gómez-Carmona CD, Hernandez A, Pino-Ortega J. Validity and reliability of an inertial device (WIMU PROTM) to tracking analysis in handball. E-Balonmano.com Rev Cienc Deporte 2018;14(1):9-16.

17. Gómez-Carmona CD, Bastida-Castillo A, García-Rubio J, Ibáñez SJ, Pino-Ortega J. Static and dynamic reliability of WIMU PROTM accelerometers according to anatomical placement. Proc Inst Mech Eng Part P J Sports Eng Technol 2019;233(2):238-248.

18. Bastida-Castillo A, Gómez-Carmona CD, De la Cruz Sánchez E, Reche-Royo X, Ibáñez SJ, Pino-Ortega J. Accuracy and inter-unit reliability of ultra-wide-band tracking system in indoor exercise. Appl Sci 2019; 9(5):939.

19. Cohen J. Statistical power analysis for the behavioral sciences. 2nd ed. Hillsdale, NJ: Lawrence Erlbaum Associates; 1988.

20. Belka J, Hulka K, Safar M, Weisser R, Samcova A. Analyses of time-motion and heart rate in elite female players (U19) during competitive handball matches. Kinesiology 2014;46(1):33-43.

21. Cardinale M, Whiteley R, Hosny AA, Popovic N. Activity profiles and positional differences of handball players during the World Championships in Qatar 2015. Int J Sports Physiol Perform 2017;12(7):908-915.

22. Barbero JC, Granda-Vera J, Calleja-González J, Del Coso J. Physical and physiological demands of elite team handball players. Int J Perform Anal Sport 2014;14(3):921-933.

23. Chelly MS, Hermassi S, Aouadi R, Khalifa R, Van den Tillaar R, Chamari K, et al. Match analysis of elite adolescent team handball players. J Strength Cond Res 2011;25(9):2410-2417. 
24. Luteberget LS, Spencer M. High-intensity events in international women's team handball matches. Int J Sports Physiol Perform 2017;12(1):56-61.

25. Manchado C, Pers J, Navarro F, Han A, Sung E, Platen P. Time-motion analysis in women's team handball: importance of aerobic performance. J Sport Health Res 2013;8(2):376-390.

26. Ramírez AG, Lemos JB, Bonilla LP, Silva AT, López ER. Analysis of the finalization of the attack in equalized games of high level handball using polar coordinates. E-Balonmano.com Rev Cienc Deporte 2013;9(2):71-89.

27. Agulló JJE, Turpin JAP, Anta RC. Tactical and historical evolution of defensive play system in hadball in situations of numerical inequality. E-Balonmano Com Rev Cienc Deporte 2012;8(2):93-104.

28. Daza G, Andrés A, Tarragó R. Match statistics as predictors of team's performance in elite competitive handball. Rev Int Cienc Deporte 2017;13(48):149-161.

29. Ferrari WR, Dos Santos JV, Vaz VPS. Offensive process analysis in handball: Identification of game actions that differentiate winning from losing teams. Am J Sports Sci 2014;2(4):92-96.

30. Miñano-Espin J, Casáis L, Lago-Peñas C, Gómez-Ruano MÁ. High Speed Running and Sprinting Profiles of Elite Soccer Players. J Hum Kinet 2017;58(1):169-76.

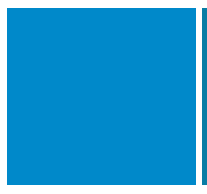

Corresponding author

Manuel Gómez-López

Department of Physical Activity and Sport, Faculty of Sport Sciences,

University of Murcia, Santiago de la Ribera, 30720 Murcia, Spain.

Email: mgomezlop@um.es 